\title{
Emotional Intelligence Influence on Employee's/Organizational Performance with Mediating Role of Job Satisfaction in Pakistani Health Sector
}

\author{
Benish Khanzada ${ }^{1}$, Shahzad Naeem ${ }^{2^{*}}$ and Hashim Butt ${ }^{3}$ \\ ${ }^{1}$ Quetta Institute of Medical Sciences, National University of Medical Sciences, Pakistan \\ ${ }^{2}$ Riphah International University, Islamabad, Pakistan \\ ${ }^{3}$ Combined Military Hospital, Medical College, Pakistan
}

*Corresponding author: Shahzad Naeem, Riphah International University, Islamabad, Pakistan, Tel: +00923335491914; E-mail: shahzadflyer@yahoo.com

Received date: March 10, 2018; Accepted date: March 28, 2018; Published date: April 04, 2018

Copyright: ( $) 2018$ Khanzada B, et al. This is an open-access article distributed under the terms of the Creative Commons Attribution License, which permits unrestricted use, distribution, and reproduction in any medium, provided the original author and source are credited.

\begin{abstract}
This study has investigated the relationship between employee's emotional intelligence and their performances mediating role of job satisfaction in Pakistani health sector. Data for this research was gathered by means of three instruments; total 432 respondents participated in this research. After data analysis, it was determined that in Pakistani health sector, employee's emotional intelligence is vital factor in determination of their performance. Correlation and linear regression analysis indicated that there is significant positive association between employee's emotional intelligence and their performance. Mediation results also highlighted that job satisfaction partially mediates between employee's emotional intelligence and their performance and strengthened their relationship.
\end{abstract}

Keywords: Emotional intelligence; Employee's performance; Job satisfaction

\section{Introduction}

In Pakistan services sectors, health sector is one of the leading sectors. Health sector effectiveness and services high quality has a positive influence on people's health. Every organization greatly depends on their employee performance and their job satisfaction level. A lot of research work has been conducted to determine impact of employee's emotional intelligence and their job satisfaction/ dissatisfaction on their performance. Relationship between emotional intelligence and job performance has acquired significant attention of researchers. Researchers have examined that employees with high job performance also possesses greater commitment [1]. Prominent organizations focus more on employee performance to stay alive in dramatically changing competitive world [2]. Thus, leaders of today require numerous skills to ensure enhanced employees' as well as organizational performance and one of the most significant skills is emotional intelligence. Researchers are of the view that leaders as well as employees with greater emotional intelligence will perform better which in result will enhance the employees as well as organizational performance $[3,4]$. Scholars have also discussed that follower with greater emotional intelligence normally demonstrate greater job performance [5]. Emotional intelligence can be defined as one's capability to recognize his emotions and other's emotions and also capability of controlling and proper reaction to these emotions. Although in research term "emotional intelligence" was previously also used but the same got popularity from book of Daniel Goleman written in 1996 on the same subject. There is difference of opinion among scholars on exact definition as well as emotional intelligence operation. Emotional intelligence three main models described by various scholars are the trait, ability, and mix model. Each model carries out measurement of emotional intelligence from diverse view but at the same time all these methods reinforces each other and are not conflicting with each other in any way [6]. Working capability of employees is not only enhanced by Emotional Intelligence (EI), but at the same time it also assist employees in managing their stress. Emotional Intelligence (EI) also assists in enhancing leadership abilities of people. Hence, understanding and demonstration of emotional intelligence is vital requirement for leaders particularly for those who have responsibility to manage organizational change as well as for employees/followers. Those leaders, who cannot manage/control their emotions effectively, may have problems in working efficiently/ effectively with followers. Available work on leadership and Emotional Intelligence (EI) strengthens the faith that surely emotional intelligence abilities help in leadership effectiveness and enhancing job/employee performance [7]. It is discussed that leaders having Emotional Intelligence (EI) skills as self-management, social and self-awareness enhance the chances for achieving organizational goals. Previous researches results in this domain indicate that greater emotional intelligence has positive impact upon leadership efficiency/ effectiveness [7]. Several researches have been conducted to investigate the impact of Emotional Intelligence (EI) on employer's as well as organizational performance/effectiveness [8,9]. Results disclosed that higher emotional intelligence leadership assisted in organizational modifications in their organizations [9]. Fambrough et al. [4] and various other prominent scholars in the fields of emotional intelligence suggested that major portion of skills required by successful leadership is Emotional Intelligence (EI) skills Fambrough et al. [4]. Mostly intellectuals agree that Emotional Intelligence (EI) skills can be gained, developed and learned through training and education [10-12]. Like other specialists, professionals of health sector also need greater level of Emotional Intelligence (EI) because daily they are required to handle/ treat many patients and come across heavy workload in comparison to any other profession. Expertise in Emotional Intelligence (EI) assists leaders employed in health sector to generate a better and healthier relationship between colleagues, team members and various other 
Page 2 of 6

staff. Historically sound technical and good clinical knowledge are considered vital for leaders, though these abilities are vital but still to ensure better results and performance of employees as well as leaders, emotional intelligence factor is considered most vital in health sector [13-15]. Piper [16] indicated that leaders of health sector require both technical and Emotional Intelligence (EI) skills for managing latest intricate healthcare provision system. Palmer et al. [17] highlighted that there is a requirement to enhance leadership emotional intelligence of health sector to ensure better clinical efficiency. Earlier researches highlight that Emotional Intelligence (EI) is positively interrelated with effectiveness of leadership and employers job performance. Emotional Intelligence (EI) factor can impact numerous job associated outcomes for example employers job performance/ satisfaction and organizational efficiency/productivity [18].

Tram et al. [19] described that employees having higher Emotional Intelligence (EI) have the capability to overcome stresses related to their job in better way and they can produce better results as compared to those employees possessing lesser emotional intelligence. Numerous researches have been carried out to examine the relationship between the emotional intelligence, job performance, employer performance and job satisfaction [6,11,19-27]. Mostly in western countries these research works were carried out and very little research work is conducted in non-Western countries particularly in Pakistani context on Emotional Intelligence (EI) and employer's job satisfaction/ performance. A detailed and wide-ranging literature review discovered that in health sector establishments very limited research works had been conducted regarding investigating the impact of Emotional Intelligence (EI) in relation to employer performance and job satisfaction. Thus, a curiosity is raised to explore answer of following questions:-

"Does Emotional Intelligence (EI) has any influence on employer performance and does job satisfaction plays any mediating role between emotional intelligence and employer performance?" This research will try to investigate following questions:-

- Does in health sector organizations Emotional Intelligence (EI) has any influence on employee's performance?

- What is mediating effect of job satisfaction on emotional intelligence and employee's performance relationship?

\section{Literature Review}

\section{Emotional intelligence (EI)}

Goleman [28] defined emotional intelligence as an "ability to monitor one's and others' feelings and emotions, to discriminate among them and to use this information to guide one's thinking and actions" (p. 189). From the time when it was originally introduced, emotional intelligence has been time and again recognized as a combination of supervisory abilities, which has a prominent control on how supervisors intermingle/cooperate with others. Mainly this situation is in the background of high project difficult environments [29-31].

Emotional intelligence forecasts leader's efficiency [30,32-37]. McCleskey [37] expressed that emotional intelligence sets free the leadership capabilities and potentials.

\section{Employee's/organizational performance}

Organization performance indicators consist of organizational ambidexterity [38] subjective comfort, happiness and burning out of place of work [39] performance of new manufactured goods, products [40] employer, worker output, efficiency [41], amongst further indicators. Appelbaum et al. [42], Boxall [43] described performance as employees function, capability, inspiration, enthusiasm and prospect to contribute or take part or participate. If these factors are properly executed, organizations are expected to take benefit of workers capabilities, potentials and unrestricted decision making ability for the purpose performance measurement. Bratton et al. [44] particularly highlighted the significance of worker's performance and conduct. For instance, workerse positive conduct permit them to gratify and provide better services to customers (for example, they move forward toward clients and tender their services and assistance), and at the same time adopt all safety practices and procedures [44]. Resultantly, on the whole workers output can supplement the organizational performance. By attaining statistics from up-and-coming organizations, Chi and Lin, [45] discovered the relation between high performance work practices and organization's performance in stipulations of expansion in sales, novelty, revenue and earnings.

\section{Relation between emotional intelligence and employee's performance}

Dunn et al. [46] established job satisfaction and trust amongst others is enhanced by positive emotions, whereas negative feelings like discontent, depression and irritation reduces job satisfaction and trust which results in reducing organizational performance. Lower emotional intelligence and responsiveness is related with greater levels of job dissatisfaction, distrust and disappointment resultantly performance of organization is effected [47]. Emotional intelligence is directly and positively linked with job satisfaction/organizational performance [48]. Emotional intelligence considerably influences the job satisfaction of other team members $[48,49]$. This fact is supported by the verification of better performance of the managers who possess high emotional intelligence as compared to those managers who possess lower emotional intelligence [48,49]. Higher emotional intelligence produces positive sentiments which in turn increase the level of job satisfaction whereas sentiments like dissatisfaction, hopelessness and annoyance decreases the level of job satisfaction [50]. As emotional responsiveness is part of emotional intelligence [28] therefore its relation with job satisfaction and resultantly effects on organizational perform is discussed. Considering above argument, it is hypothesized that:

Hypothesis 1: Emotional Intelligence is positively related to Employee's Performance.

\section{Mediating role of job satisfaction}

Tetteh et al. [51] defined job satisfaction as employer mind-set towards their work. Job satisfaction is pleasurable or positive emotional situation which results from the appraisal of employer's professional experience and their work [52], Tetteh et al. [51] indicated that employees appeared to be more satisfied with their job if they found their job is rewarding and gratifying. Employee's job satisfaction is usually considered as vital element of employer performance and organizational success. Employer job satisfaction ultimately effects employer's job performance and his obligations towards organizational which gives assurances organizational success [53]. To clarify job 
Page 3 of 6

satisfaction, characteristics associated to work are not enough to comprehend rather we need to understand employer's personality [52,54]. Belias et al. [53] described work satisfaction five angles such as: promotion, coworkers, supervision, job itself and pay package. Successful organizations normally have satisfied employers while poor job satisfaction results in organizational failure. On the foundation of the arguments argued above, study proposes that emotional intelligence assists to enhance job satisfaction, which resultantly would positively influence employee's performance (Figure 1). Job satisfaction therefore may play a mediating role in the relationship between emotional intelligence and employee's performance [19]. It is important to investigate this link, as relatively little empirical research has focused on the mediating role of job satisfaction such a steambuilding in the relationship between emotional intelligence level of leadership as well employees and employee's performance [19,52]. Hence, we offer the following hypothesis:

Hypothesis 2: Job satisfaction mediates the relationship between emotional intelligence and employee's performance.

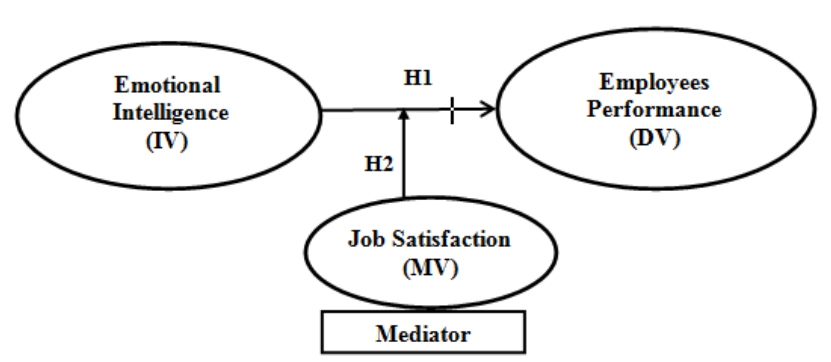

Figure 1: Conceptual Framework of the Study.

The above research model is showing relationship between Independent Variable (IV), Dependent Variable (DV) and Mediating Variable (MV). Here, Emotional Intelligence (EI) is working as IV, Employee's Performance as (DV) and Job satisfaction as Mediator (MV). The model is showing that emotional intelligence is positively influencing employees performance and Job satisfaction mediates the relationship between Emotional intelligence and employees performance, on this basis $\mathrm{H} 1, \mathrm{H} 2$ are derived.

\section{Methodology}

\section{Pilot study}

Present research objectives were attained in two stages. Firstly a pilot study was carried out to pretest the research instruments. At second stage, main research was executed. Pilot study was carried out with an aim of development a comprehensive study design and secondly to check instruments reliability of emotional intelligence, employee performance and job satisfaction. Other aim of pilot study was improving the questionnaire and check respondent's reaction to given 5-point Likert scale.

The aim of this research is to establish the influence of Emotional Intelligence (EI) on employee's performance with mediating role of employee's job satisfaction working in health sector of Pakistan. Questionnaire technique was used for data collection. Questionnaire of emotional intelligence (IV) was adopted. One sample item is "I always know my friends' emotions from their behavior".
Questionnaire of emotional intelligence was comprised of 4 items and five point Likert scale from $1=$ Strongly Disagree to $5=$ Strongly Agree was used to measure this variable. Job satisfaction (Mediating Variable) questionnaire was adopted from Judge, Timothy A. (20000). Job satisfaction questionnaire of was comprised of 5 items and same five point Likert scale from $1=$ Strongly Disagree to $5=$ Strongly Agree was used to measure this variable. The questionnaire of employee's performance (DV) was adopted from [19]. Questionnaire of employees performance was comprised of 8 items and five point Likert scale from $1=$ Worst to $5=$ Excellent was used to measure this variable (Table 1).

To check the reliability and validity of questionnaire initially 30 questionnaires were distributed for pilot testing. The reliability scores after pilot testing reported against each variable is as under:-

\begin{tabular}{|l|l|}
\hline Variable & Cronbach Alpha \\
\hline Emotional Intelligence (EI) & 0.876 \\
\hline Job Satisfaction (JS) & 0.619 \\
\hline Employees Performance (EP) & 0.732 \\
\hline
\end{tabular}

Table 1: The reliability scores after pilot testing reported against each variable.

Keeping the aim of this research in view, private hospitals located in Lahore, Rawalpindi and Islamabad were selected as research population. Keeping in view time and budget constraints, technique of convenient sampling was adopted. Hospital employees were contacted on basis of personal contact and topic relevancy of research (Table 2). Most of the respondents are either employees or on managerial positions in selected hospitals. Personally administered questionnaire were disseminated among 40 hospital employees in out of which 274 were returned back and only 252 usable. The response rate was $63 \%$.

\begin{tabular}{|c|c|c|c|}
\hline & & Frequency & Percentage \\
\hline \multirow{2}{*}{ Gender } & Male & 41 & $16 \%$ \\
\hline & Female & 211 & $84 \%$ \\
\hline \multirow{3}{*}{ Qualification } & Graduation & 97 & $38 \%$ \\
\hline & Masters & 145 & $57.50 \%$ \\
\hline & Others & 10 & $3.97 \%$ \\
\hline \multirow{4}{*}{ Age } & $20-30$ & 86 & $34.10 \%$ \\
\hline & $31-40$ & 154 & $61.10 \%$ \\
\hline & $41-50$ & 10 & $3.97 \%$ \\
\hline & $51-60$ & 2 & $0.80 \%$ \\
\hline \multirow{4}{*}{ Experience } & $0-2$ yrs & 51 & $20.20 \%$ \\
\hline & $3-5$ yrs & 104 & $41.30 \%$ \\
\hline & $6-10$ & 47 & $18.60 \%$ \\
\hline & Above 10 yrs & 50 & $19.80 \%$ \\
\hline
\end{tabular}

Table 2: Demographic Analysis.

To test the research model, a survey was conducted, identified from a list of participants selected. The sample size was $252.16 \%$ of the 
respondents of this research were male, while $84 \%$ were female. Furthermore, $34.1 \%$ of the respondents were between age group of 20-30 years, $61.1 \%$ were between $31-40$ years, $3.97 \%$ were between 41-50 years and $0.8 \%$ was between 51-60 years. With regard to qualification of respondents $38 \%$ respondents were graduated, $57.5 \%$ respondents were master degree holders and $3.97 \%$ of the respondents belonged to others category. Respondents having experience $0-2$ years comprised $20.2 \%$ of the sample, 3-5 years experienced respondents were $41.3 \%$, 6-10 years experienced respondents comprised $18.6 \%$, whereas, $19.8 \%$ of the sample showed respondents having experience above 10 years.

\section{Results}

Research study results and findings are discussed as under. Furthermore, in analysis section correlation and regression analysis were carried out.

\begin{tabular}{|l|l|l|l|}
\hline Variables & $\mathbf{1}$ & $\mathbf{2}$ & $\mathbf{3}$ \\
\hline Emotional Intelligence & 1 & & \\
\hline Job Satisfaction & $0.233^{* *}$ & 1 & \\
\hline Employees Performance & $0.592^{* *}$ & $0.349^{* *}$ & 1 \\
\hline${ }^{*} \mathrm{p}=0.05 ;{ }^{* *} \mathrm{p}=0.01$ & & \\
\hline${ }^{* *}$ Correlation is significant at the 0.01 level (2-tailed)
\end{tabular}

Table 3: Correlation Analysis.

In Table 3 correlation analysis shows the relationship between variables emotional intelligence, job satisfaction and employees performance. The correlation between emotional intelligence and job satisfaction is $0.233^{* *}$, which indicates significant and positive correlation between both variables. The correlation between emotional intelligence and employees performance is $0.592^{\star *}$, which mean there is significance and positive correlation between both variables. Similarly, the correlation between job satisfaction and employees performance is $349^{\star *}$, which ascertains significance as well as positive correlation between both variables.

\begin{tabular}{|l|l|l|l|}
\hline \multirow{2}{*}{ Predictor } & \multicolumn{2}{l}{ Outcome } \\
\cline { 2 - 4 } & \multicolumn{2}{l}{ Project Success } & \multicolumn{2}{l|}{ R2 } \\
\cline { 2 - 4 } & $\boldsymbol{\beta}$ & $\mathbf{R} 2$ & 035 \\
\hline Step I Control Variables & & 35 & 0.111 \\
\hline Step II Job Satisfaction & 0.222 & 0.147 & 0.264 \\
\hline $\begin{array}{l}\text { Step III Transformational } \\
\text { Leadership }\end{array}$ & 0.54 & 0.412 & \\
\hline a. Predictors: (Constant); Age; Experience; Gender; Qualification \\
\hline b. Predictors: (Constant); Age; Experience; Gender; Qualification; JSM \\
\hline \multicolumn{2}{|l|}{ c. Predictors: (Constant); Age; Experience; Gender; Qualification; JSM; EIM } \\
\hline
\end{tabular}

Table 4: Mediated Regression Analysis.

Table 4 indicates the results of Barron and Kenny mediated aggression analysis. The result shows the significance between direct relationship between emotional intelligence and employee's performance. After incorporating the mediator, i.e., job satisfaction, the change in $\mathrm{R}^{2}$ occurs at 0.111 , which is significant, thus showing that job satisfaction, mediates the relationship between emotional intelligence and employee's performance, leading to the acceptance of hypothesis 2 .

\begin{tabular}{|l|l|l|}
\hline & $\boldsymbol{\beta}$ & $\mathbf{t}$ \\
\hline El to JS (a) (IV to Mediator) & $0.1683^{* *}$ & 3.0615 \\
\hline JS to EP (b) (Mediator to DV) & $0.3136^{\star \star}$ & 3.0897 \\
\hline El to EP (c) (IV to DV) & $0.6124^{* \star}$ & 8.8531 \\
\hline El to EP (c') (IV to DV) & $0.5596^{\star *}$ & 8.068 \\
\hline${ }^{*} \mathrm{p}=0.05,{ }^{* *} \mathrm{p}=0.01$ & & \\
\hline
\end{tabular}

Table 5: Mediation.

Table 5 shows the results of indirect process analysis. The result indicates job satisfaction partially mediates the relationship between emotional intelligence and employee's performance, leading to acceptance of hypothesis 2 .

\section{Discussion}

The purpose of this study was to find the linkage between emotional intelligence and employee's performance through mediation of job satisfaction. As anticipated, it was found that manager's/employers emotional intelligence plays a significant role in employer's performance. Manger/employers with emotional intelligence qualities have better job performance through efficacy, effectiveness, efficiency and job satisfaction. This finding of current research supports and concur the previous literature that emotional intelligence is positively related to employers performance $[19,55]$ which leads to acceptance of Hypothesis 1: According to the research, reasons for accepting the $\mathrm{H} 1$ are that if managers/employers use their emotional intelligence, they can improve their efficiency which will ultimately results in success of organization.

Mediation hypothesis proposed that job satisfaction mediates the relationship between emotional intelligence and employer's performance. The results not only lead to the acceptance of hypothesis but also supported by previous literature. As existing literature established that job satisfaction is observed as the key to enhance employer's performance which resultantly lead towards organizational success $[56,57]$.

\section{Theoretical and Practical Implications}

This research will contribute in literature of project management by integrating emotional intelligence and job satisfaction model. Research work results highlight that job satisfaction mediates between emotional intelligence and employee's performance. This research work will enhance understanding of readers regarding emotional intelligence and job satisfaction in jeopardizing employers' performance. As expected, emotional intelligence was important statistically in explaining employer's performance, both without and with job satisfaction as mediator. This research work will assists to unearth how emotional intelligence can supplement the employer's performance by exhibiting vital role of job satisfaction. Leaders with higher emotional intelligence are helpful in developing job satisfaction 
amongst employees, which resultantly help in increasing employer's performance at work. This indicates that positive effect of higher emotional intelligence on employer's performance will be more reinforced if organization also aids in encouraging job satisfaction amongst their staffs. Finding of this research work indicates that the job satisfaction mediates partially, which shows that there are other factors which also work behind the association among emotional intelligence and employer's performance.

To a certain extent few other implications can also be taken out from findings of this research work such as that managers/employer's higher emotional intelligence level will augment their performance through job satisfaction. This finding is alike to earlier work findings indicating positive relation among emotional intelligence and employer's performance $[58,59]$. A further practical implication of this research is that managers/employers should be given emotional intelligence training [19] which is likely to improve employer's performance which will resultantly enhance chances of organizational success. This research work also highlights that leadership/employer's emotional intelligence training should be focused on developing job satisfaction amongst employers to gain utmost benefits.

\section{Limitations and Directions for Future Research Directions}

This research has numerous limitations which should be given due attention while deducing the findings. First limitation was due to time limit comparatively smaller sample was gathered from hospitals situated at Lahore, Rawalpindi and Islamabad only, thus data collection from all over the country with a bigger sample will overcome the above highlighted limitation and at the same time it will also provide a complete and comprehensive picture.

Second limitation is related to method of data collection. Hence, data was collected by only questionnaire technique. Thus, it is recommended that future study must collect data by multiple ways.

Third limitation of the research is collection of cross sectional data using convenience sampling technique due to time constraint. It is suggested that future researches must gather data using time lag.

Even though, aim of this research has been attained but for future study more pertinent variables related to employer's performance can be incorporated. Moreover, in future researches assessment of the results of employer's performance on organizational performance can further explain the relationship.

\section{References}

1. Burns GN, Kotrba LM, Denison DR (2013) Leader-culture fit: Aligning leadership and corporate culture. Wiley-Blackwell handbooks in organizational psychology. The Wiley-Blackwell handbook of the psychology of leadership, change, and organizational development, pp: 113-128.

2. Dawkins R (2016) The selfish gene. Oxford University Press.

3. Mandell B, Pherwani S (2003) Relationship between emotional intelligence and transformational leadership style: A gender comparison. J Bus Psychol 17: 387-404.

4. Fambrough MJ, Kaye Hart R (2008) Emotions in leadership development: A critique of emotional intelligence. Advances in Developing Human Resources 10: 740-758.

5. James V, LaMotta C (2002) Why do smart people fail. Emotional intelligence can get you a competitive edge. Direct, p: 52 .
6. Mayer JD, Salovey P (2007) Mayer-Salovery-Caruso emotional intelligence test. Multi-Health Systems Incorporated.

7. Kerr R, Garvin J, Heaton N, Boyle E (2006) Emotional intelligence and leadership effectiveness. Leadersh Organizat Dev J 27: 265-279.

8. Brown ME, Treviño LK (2006) Ethical leadership: A review and future directions. Leadersh Quart 17: 595-616.

9. Riggio RE, Reichard RJ (2008) The emotional and social intelligences of effective leadership: An emotional and social skill approach. J Manag Psychol 23: 169-185.

10. Browning H, Torain DJ, Patterson TE (2011) Collaborative healthcare leadership: A six-part model for adapting and thriving during a time of transformative change. Center for Creative Leadership White Papers.

11. Crowne KA (2009) The relationships among social intelligence, emotional intelligence and cultural intelligence. J Manag Organization 6: 148-163.

12. Morrow PC, McElroy JC, Scheibe KP (2011) Work unit incivility, job satisfaction, and total quality management among transportation employees. Transportation Research Part E: Logistics and Transportation Review 47: 1210-1220.

13. Jones SM (2007) Emotional intelligence within organizations: A study of emotional intelligence and performance ranking within a biomedical company (Doctoral Dissertation, Pepperdine University).

14. Bartlett JA (2013) Back to the Classics: A Library Leader's Basic Management Bookshelf. Library Leadersh \& Manag 28: 1.

15. Vitello-Cicciu JM (2002) Exploring emotional intelligence: implications for nursing leaders. J Nurs Administ 32: 203-210.

16. Piper LE (2008) The generation-Y workforce in health care: The new challenge for leadership. The Health Care Manag 27: 98-103.

17. Palmer PN, Jansen CA (2004) Emotional intelligence as an important attribute of transformational Leadership. In Southern African Institute of Management Scientist Annual Conference, pp: 17-29.

18. Suliman AM, Al-Shaikh FN (2007) Emotional intelligence at work: Links to conflict and innovation. Employee Relat 29: 208-220.

19. Sy T, Tram S, O'Hara LA (2006) Relation of employee and manager emotional intelligence to job satisfaction and performance. J Vocat Behav 68: 461-473.

20. Mayer JD, Salovey P, Caruso DR (2004) Target Articles:" emotional Intelligence: theory, findings, and implications". Psychol Inq 15: 197-215.

21. Liepold MJ, Rasmussen C, Boyce K, Trudeau-Poskas D (2013) Outside the Comfort Zone: Strategies for Developing Emotionally Intelligent Leaders, pp: 74-87.

22. Rotenberry PF, Moberg PJ (2007) Assessing the impact of job involvement on performance. Manag Res News 30: 203-215.

23. Islam T, ur Rehman S, Ahmed I (2013) Investigating the mediating role of organizational politics between leadership style and followers' behavioral outcomes. Bus Strategy Ser 14: 80-96.

24. Antonakis J, Ashkanasy NM, Dasborough MT (2009) Does leadership need emotional intelligence?. leadersh Quart 20: 247-261.

25. Golparvar M, Khaksar F (2010) The relationship between emotional intelligence and job performances in a set of industrial factories in Isfahan.

26. Sakurai K, Jex SM (2012) Coworker incivility and incivility targets' work effort and counterproductive work behaviors: The moderating role of supervisor social support. J Occupat Health Psychol 17: 150.

27. Ejere EI, Abasilim UD (2013) Impact of transactional and transformational leadership styles on organisational performance: Empirical evidence from Nigeria. J Commer 5: 30-41.

28. Goleman D (2006) Emotional intelligence. Bantam.

29. Mayer JD, Salovey P, Caruso DR (2008) Emotional intelligence: New ability or eclectic traits?. American Psychol 63: 503.

30. O'Boyle EH, Humphrey RH, Pollack JM, Hawver TH, Story PA (2011) The relation between emotional intelligence and job performance: A meta-analysis. J Organizat Behav 32: 788-818. 
Citation: Khanzada B, Naeem S, Butt H (2018) Emotional Intelligence Influence on Employee's/Organizational Performance with Mediating Role of Job Satisfaction in Pakistani Health Sector. J Health Educ Res Dev 6: 253. doi:10.4172/2380-5439.1000253

Page 6 of 6

31. Yang LR, Huang CF, Wu KS (2011) The association among project manager's leadership style, teamwork and project success. Int J Proj Manag 29: 258-267.

32. Miao C, Humphrey RH, Qian S (2017) A meta-analysis of emotional intelligence and work attitudes. J Occupat Organizat Psychol 90: 177-202.

33. Ashkanasy NM, Daus CS (2005) Rumors of the death of emotional intelligence in organizational behavior are vastly exaggerated. J Organizat Behav 26: 441-452.

34. Grandy G (2013) An exploratory study of strategic leadership in churches. Leadersh Organizat Develop J 34: 616-638.

35. Obradovic V, Jovanovic P, Petrovic D, Mihic M, Mitrovic Z (2013) Project managers' emotional intelligence-a ticket to success. Proc-Soc Behav Sci 74: 274-284.

36. Gugliandolo MC, Costa S, Cuzzocrea F, Larcan R, Petrides KV (2015) Trait emotional intelligence and behavioral problems among adolescents: A cross-informant design. Personal Indiv Diff 74: 16-21.

37. McCleskey J (2014) Emotional intelligence and leadership: A review of the progress, controversy, and criticism. Int J Organizat Anal 22: 76-93.

38. Junni P, Sarala RM, Taras V, Tarba SY (2013) Organizational ambidexterity and performance: A meta-analysis. Acad Manag Perspect 27: 299-312.

39. Stoia E (2016) Happiness and well-being at work.

40. Chiang YH, Shih HA, Hsu CC (2014) High commitment work system, transactive memory system, and new product performance. J Bus Res 67: 631-640.

41. Stirpe L, Bonache J, Revilla A (2014) Differentiating the workforce: The performance effects of using contingent labor in a context of highperformance work systems. J Bus Res 67: 1334-1341.

42. Appelbaum E, Bailey T, Berg P, Kalleberg A (2000) Manufacturing competitive advantage: The effects of high performance work systems on plant performance and company outcomes. Manufacturing advantage: Why high-performance work systems pay off. NY: Cornell University Press.

43. Boxall P (2003) HR strategy and competitive advantage in the service sector. J Human Res Manag 13: 5-20.

44. Bratton J, Gold J (2017) Human resource management: theory and practice. Palgrave.

45. Chi NW, Lin CYY (2011) Beyond the High-Performance Paradigm: Exploring the Curvilinear Relationship between High-Performance Work Systems and Organizational Performance in Taiwanese Manufacturing Firms. Briti J Indust Relat 49: 486-514.
46. Dunn JR, Schweitzer ME (2005) Feeling and believing: the influence of emotion on trust. J Personal Soc Psychol 88: 736.

47. Boden MT, Berenbaum H (2007) Emotional awareness, gender, and suspiciousness. Cognit Emot 21: 268-280.

48. Christie AM, Jordan PJ, Troth AC (2015) Trust antecedents: emotional intelligence and perceptions of others. Int J Organizat Anal 23: 89-101.

49. Barczak G, Lassk F, Mulki J (2010) Antecedents of team creativity: An examination of team emotional intelligence, team trust and collaborative culture. Creat Innovat Manag 19: 332-345.

50. Jordan PJ, Lawrence SA, Troth AC (2006) The impact of negative mood on team performance. J Manag Organizat 12: 131-145.

51. Tetteh EN, Brenyah RS (2016) Organizational leadership styles and their impact on employees' job satisfaction: Evidence from the mobile telecommunications sector of Ghana. Glob J Human Res Manag 4: 12-24.

52. Naeem S, Khanzada B (2017) Impact of Transformational Leadership in Attainment of Project Success: The Mediating Role of Job Satisfaction. Int J Bus Soc Sci 8: 168-177

53. Belias D, Koustelios A, Vairaktarakis G, Sdrolias L (2015) Organizationa culture and job satisfaction of Greek banking institutions. Proc-Soc Behav Sci 175: 314-323.

54. Rezvani A, Chang A, Wiewiora A, Ashkanasy NM, Jordan PJ, et al. (2016) Manager emotional intelligence and project success: The mediating role of job satisfaction and trust. Int J Proj Manag 34: 1112-1122.

55. Wong CS, Law KS (2002) The effects of leader and follower emotional intelligence on performance and attitude: An exploratory study. Leadersh Quart 13: 243-274.

56. Christen M, Iyer G, Soberman D (2006) Job satisfaction, job performance, and effort: A reexamination using agency theory. J Market 70: 137-150.

57. Ibrahim ME, Al Sejini S, Al Qassimi OAA (2004) Job satisfaction and performance of government employees in UAE. J Manag Res 4: 1.

58. Fernandez R, Salamonson Y, Griffiths R (2012) Emotional intelligence as a predictor of academic performance in first-year accelerated graduate entry nursing students. J Clin Nurs 21: 3485-3492.

59. Saeed I, Waseem M, Sikander S, Rizwan M (2014) The relationship of turnover intention with job satisfaction, job performance, leader member exchange, emotional intelligence and organizational commitment. Int J Learn Develop 4: 242-256. 